\title{
Psicanálise e Política: O Trabalho Da Desilusão
}

\author{
Alexei Conte Indursky1 \\ Bárbara de Souza Conte2
}

\section{Resumo}

O presente ensaio propõe-se a discutir qual a postura ética que a psicanálise herda de Sigmund Freud sobre como posicionar-se frente a fenômenos políticos autoritários. Inicialmente, realizamos uma leitura do bolsonarismo a partir de uma revisão do mecanismo de identificação ao líder proposto por Freud. Para tanto, são abordadas as noções de fascismo e populismo, desenvolvidas respectivamente por Theodor Adorno e Ernesto Laclau, decantando daí três operadores fundamentais à emergência desse fenômeno: identificação narcísica, retórica vitimista e "religiosização da política". Por fim, debatemos a importância do trabalho da desilusão como condição necessária para a elaboração da necessidade da crença.

PALAVRAS-Chave: Identificação; desilusão; fascismo; populismo.

1Psicanalista. Doutor em Psicanálise e Psicopatologia pela Universidade Paris 7, Sorbonne. Membro da Associação Psicanalítica de Porto Alegre. E-mail: alexei.indursky@gmail.com

2 Psicanalista. Doutora em Psicologia pela Universidade Autônoma de Madri. Membro Pleno da Sigmund Freud Associação Psicanalítica. E-mail: bdesouzaconte@gmail.com 


\section{INTRODUÇÃO}

Em 1933, o analista Eduardo Weiss chega em Viena acompanhado de uma de suas pacientes, a fim de solicitar a Freud sua ajuda na direção da cura desse caso. Junto com ela, estava seu pai Giovacchino Forzano3, escritor e diretor de teatro, que recentemente ficara íntimo de Benito Mussolini, com quem havia escrito uma peça sobre Napoleão. No intuito de seduzir Freud, a quem ele confiava o destino de sua filha, Forzano trazia consigo uma edição dessa obra autografada com a seguinte dedicatória: "A S.F. que tornará o mundo melhor, com admiração e reconhecimento". Em retorno a seu gesto, Forzano pediu uma foto com Freud e um de seus livros, escolhido pelo próprio Herr Professor, com uma dedicatória a ser endereçada ao Duce Mussolini. Freud vai a sua biblioteca e seleciona um exemplar de "Por que a guerra?" e escreve: "A Benito Mussolini com as humildes saudações de um velho homem que reconhece no homem de poder um campeão da cultura [kulturheros]" 4.

Essa cena, trazida por Elisabeth Roudinesco (2011) é um dos poucos testemunhos sobre a postura de Freud quando confrontado com temas políticos. Sua recusa de indicar um lugar de filiação política foi durante muito tempo interpretada como "apolítica", isto é, espécie de neutralidade, cuja condição de possibilidade seria possível somente pelo gesto de vestir-se das lentes de um "humanismo agnóstico", do qual Freud sempre foi um entusiasta. Certamente, foi à sombra desse humanismo que ele pretendeu decifrar as montagens da Cultura e do desastre dos ideais culturais que engendraram o nazi-fascismo.

A ciência representava para Freud uma possibilidade de recuo da dimensão política, pois, à luz do Universal que sobrevoa problemas "mundanos", em que a Cultura representava ganho civilizatório ipso facto, a ciência permitia abster-se de pensar sobre as implicações políticas de sua incidência na reprodução material da vida psíquica e na estrutura dos sistemas simbólicos da cultura. A política estava assim no campo do poder, ao passo que a psicanálise procurava situar-se no campo da cultura. Campos que, contudo, não cessavam a demonstrar suas encruzilhadas. 
Essa postura freudiana parece prenhe de sentidos e efeitos equívocos até os dias de hoje. Muito antes de indicar um apoio ao Duce - como insinua Michel Onfray (2009) - podemos notar no gesto freudiano uma posição irônica, como forma de interpelar o poder, presente no próprio texto ofertado a Mussolini.

Em "Por que a guerra?" Freud (1932/1974) sugere a Einstein trocar a palavra poder (macht) por violência (gewalt), lembrando que direito e violência, ainda que pareçam opostos, comungam de uma mesma origem. Desta forma, Freud justifica como o direito que funda o Estado é um direito calcado no monopólio da violência, fato que frente ao fracasso das funções dos ideais, não raro engendra montagens perversas contra seus cidadãos, expondo-os à desmesura da violência. Ou seja, na gramática de seu tempo, pensar a política significava para Freud interpelar o herói (kulturheros) que ocupa a posição limítrofe entre cultura e barbárie; que tanto pode inspirar a identificação, quanto a hostilidade do povo, tanto o ganho civilizatório, quanto a suspensão da lei.

Atualmente testemunhamos tempos sombrios, em que a emergência de novos projetos políticos de cunho autoritário e desumanizante coloca novamente a psicanálise frente ao compromisso de posicionar-se. No entanto, essa convocatória a um posicionamento ético tem engendrado um efeito rebote significativo, encontrado em discursos que sugerem que psicanalistas são "socialistas" disfarçados, cuja prática profissional estaria voltada à "doutrinação" de pacientes5. De forma que o bordão "Psicanálise sem partido" já é uma realidade.

Se a postura apolítica de Freud - que duvidava tanto dos projetos de esquerda quanto de direita - buscava se resguardar de tornar-se uma visão de mundo (weltanschauung), atualmente esse receio freudiano parece mais justificado do que nunca. Apostemos: que a psicanálise tenha se pretendido apolítica, não implica, por consequência, uma espécie de indiferença política ou ainda recusa a qualquer posicionamento nesse campo - questão mais ampla e complexa do que a simples aderência a causas ou partidos específicos. Reparemos: no mesmo texto das Novas Conferências em que é afirmado que a psicanálise não deve tornar-se uma "visão de mundo" há uma passagem muito menos lembrada. Nela, Freud defende que a

5 Ver, por exemplo, o vídeo de Rodrigo Constantino: https://www.youtube.com/watch?v=eBZggdYQAQ 
psicanálise "não pode furtar-se ao mundo cultural, histórico e social de que faz parte; em consequência disso, ela tem que adotar (annehmen) a visão de mundo (weltanschauung) correspondente à "apreciação geral" nos campos em que não tem uma experiência específica" (FREUD, 1932/1971, p.212).

A proposta desse escrito vem, nesse sentido, ciosa da complexidade e dos perigos que nossos tempos sombrios nos impõem. Como relançar a postura freudiana frente a tais perigos? Qual leitura que a psicanálise pode realizar da emergência do fenômeno político do bolsonarismo?

\section{De Um Populismo Patético Como Sintoma Da Ruptura Democrática}

Podemos observar atualmente uma divisão na crítica brasileira entre duas formas de analisar o bolsonarismo. Por um lado, identificamos uma série de argumentos que sugerem a utilização do "fascismo" como operador conceitual central de análise. Por outro, uma tendência a analisar a figura de Bolsonaro como uma figura patética, desprovida de capacidade de governo que seria, em última instância, um mero "avatar" a serviço da elite brasileira.

De uma forma geral, os argumentos a favor dessa identificação se distribuem na analogia entre circunstâncias que permitiram a emergência de novos líderes políticos de ultradireita no século passado e em nossa atualidade. A recessão econômica mundial que advêm desde 2008 transformou o estado de excepcionalidade da crise em modus operandi normal da gestão do Estado democrático. Nesse contexto global, a eleição de Jair Bolsonaro emerge de uma situação de instabilidade econômica e descrédito com a classe política no Brasil que, após a deposição da presidenta Dilma, através de um impeachment instrumentalizado pela Câmara e Congresso, e do desmantelamento da principal liderança do Partido dos Trabalhadores pela operação Lava-Jato, se apresenta como uma espécie de purificação e higienização da "velha política", trazida curiosamente pelas "mãos limpas" de um sujeito que esteve 28 anos na Câmara dos deputados, com apenas um projeto aprovado. Ou seja, teríamos aí todos os elementos estruturais para realizar essa comparação: crise econômica, esvaziamento da política, apoio das oligarquias à líderes carismáticos, captura do poder judiciário... 
Do lado das teses que procuram nuançar essa identificação do bolsonarismo ao fascismo, encontramos a crítica de que Bolsonaro não corresponde ao retorno do mesmo estilo de figuras autoritárias que marcaram os fenômenos nazifascistas do século XX. Ou seja, haveria uma distância considerável entre o fantasma do ditador e os novos presidentes de ultradireita.

Um exemplo disso seria o movimento Escola sem Partido. A comparação feita entre a censura ideológica promovida pelos simpatizantes do governo e a prática da censura na ditadura civil-militar sugeria a princípio essa identificação. No entanto, como argumenta Miguel Lago em matéria à Piauí de maio 2019: "Para combater essa pretensa prática [de doutrinação], alunos foram incentivados a filmar seus professores e a constrangê-los. Caso isso de fato ocorresse, a figura de autoridade e a relação de hierarquia entre mestre/aluno seria imediatamente quebrada. Uma política de educação conservadora, ao contrário, estaria focada em fortalecer a figura de autoridade do professor dentro de aula..." (LAGO, 2019)6.

Segundo o autor, entre a figura autoritária e suas práticas de censura, encontraríamos supostamente uma distância considerável que, ao invés de inflar e saturar as figuras clássicas da autoridade, como a do professor, acaba expondo-as ao ridículo7. Nessa esteira, certas leiturass chegam a afirmar que Bolsonaro seria uma espécie de 'avatar' ou 'fantoche' de interesses de uma elite econômica cansada de ser boazinha e que presume que possa controlar seu títere a uma distância segura. $O$ que, aliás, efetivamente ocorreu com as elites europeias na década 20 do século passado, que de forma trágica acaram pavimentando o caminho para o arbítrio de Mussolini e Hitler.

Se essas leituras parecem acertar na análise fenomenológica dos traços que constituem o novo perfil dos líderes autoritários do século XXI, elas parecem errar o alvo no que concerne às transformações de nosso laço social, da forma perversa

\footnotetext{
6 Disponível em : https://piaui.folha.uol.com.br/materia/procura-se-um-presidente/

7 Os exemplos, nesse sentido, são incontáveis: a demissão do ministro da Educação Velez, o acordo para migração de cidadãos estadunidenses ao Brasil sem exigência de reciprocidade, o gesto de apoio à Netanyahu que prejudica as relações econômicas com países árabes, as quedas de braço com a Câmara, nas quais os filhos de Bolsonaro prejudicam, senão inviabilizam, a mediação de Rodrigo Maia para a aprovação da previdência, o desgaste entre seu guru astrólogo e a banda militar, etc.

8 Ver por exemplo o editorial de Mino Carta: https://www.cartacapital.com.br/opiniao/bolsonaro-nao-eultradireitista-soberanista-fascista-ele-e-demente/
} 
como se expressa a autoridade e suas formas de gozo em nossa atualidade. Certamente, Bolsonaro é uma figura patética que não se apresenta nem com a mesma retórica, nem com o mesmo projeto político fascista. No entanto, e essa é a posição que gostaríamos de defender, longe de isso ser um demérito, ou uma desqualificação de sua figura, isso tem se apresentado como um de seus principais trunfos. Nossa posição no presente ensaio é de que, como na maioria dos debates promovidos em torno da figura de Bolsonaro, essa é uma falsa discussão que nos faz perder de vista o real problema que estamos enfrentando.

Para melhor abordarmos essa questão, retomemos a justificativa com que Ernesto Laclau (2013) começa sua leitura sobre a razão populista:

\begin{abstract}
"em vez de contrapor "vagueza" e "inconsistência" a uma lógica política madura, governada por um alto grau de determinação institucional [...], deveríamos começar a colocar para nós mesmos um conjunto mais básico e diferente de perguntas: a "vagueza" dos discursos políticos populistas não é consequência da própria realidade social que, em algumas situações é vaga e indeterminada? Nesse caso, o populismo, mais do que uma tosca operação política e ideológica, não seria um ato performativo dotado de racionalidade própria, isto é, em determinadas situações a vagueza não seria precondição para a construção de significados políticos relevantes?" (LACLAU, 2013, p.53).
\end{abstract}

Aceitando a provocação de Laclau, deveríamos estar nos perguntando como ler a emergência de Bolsonaro como uma série de atos que performatizam a vagueza e indeterminação de nosso laço social. Isto é, como ler o bolsonarismo como o sintoma populista da ruptura democrática que vivemos desde o impeachment da presidenta Dilma, a partir do qual passamos a ser confrontados com o que há de mais espúrio e perverso na política.

Eliane Brum (2019) propõe a definição de Bolsonaro como anti-presidente, cujo principal objetivo seria o de governar o país como uma milícia contra a nação, criando sua própria oposição, sequestrando o debate público e deixando o país no rumo político de sua própria vontade. Nossa aposta é de que entender o bolsonarismo como um antigoverno (o que não significa dizer que ele é um "avatar") nos permite entender como ele tem se utilizado deliberadamente de uma retórica vitimista e patética como forma de governo, que promove sem cessar a circulação da desordem e da insegurança como manutenção de uma identificação com seus apoiadores.

Analisar esse processo inconsciente das identificações que permitiram a emergência do bolsonarismo nos parece fundamental, sobretudo, porque a estratégia 
de denúncia e rotulação de 'fascistas' ou 'bolsominions' dirigida aos entusiastas de medidas de ultradireita não parecem surtir um efeito positivo de crítica e tomada de consciência da desumanização que estamos testemunhando. Pelo contrário, a rotulação de 'bolsominion' deixa escrachada a falência da crítica frente a discursos cínicos que autorizam o sujeito a perverter o que até então era interdito. Ou seja, a rotulação de fascista deixou de produzir um efeito performativo de responsabilização e não repetição da barbárie que possuía até o início do século, passando apenas a reproduzir as clivagens de nosso laço social.

Portanto, a tarefa aqui é menos ontológica do que ética: como desmontarmos o discurso cínico para melhor entender como confrontá-lo?

\section{Desresponsabilização E Vitimismo: Fontes da IDentificação BOLSONARISTA}

Se nossa leitura do bolsonarismo como um populismo patético é plausível, duas questões se impõem: por que nossas democracias parecem destinadas a reviver figuras arcaicas do poder? Quais as fontes dessa identificação?

É a partir da leitura de "Psicologia das Massas e análise do Eu" que Theodor Adorno (2007) realiza em 1949 uma análise remarcável sobre a propaganda política do Terceiro Reich. Frente ao contexto do pós-guerra de uma Alemanha humilhada, em plena crise econômica e cuja autoridade paterna encontrava-se em pleno declínio, Adorno soube mostrar, a partir de Freud, como as figuras sociais paternas não simplesmente desaparecem em tais circunstâncias, mas são investidas pela política com a promessa de retorno de um pai forte e arcaico, que não precisaria se submeter aos imperativos de repressão e do politicamente correto. Adorno mostrou que o que fazia com que cidadãos alemães, que não desejavam necessariamente realizar um genocídio depositassem sua fé num líder tirânico, era precisamente uma lógica ressentida que vinculava o culto da pureza germânica à mecanismos de segregação das raças impuras, em nome do reestabelecimento da soberania e da segurança perdida.

No entanto, o que essa nova soberania promoveu não foram necessariamente novas e melhores leis de proteção e segurança do povo, mas a possibilidade de que essas leis poderiam ser suspensas e "transgredidas controladamente" ao sabor da 
vontade do Fürer. Pois, se o que liga o sujeito ao líder é um traço de identificação, o fundamento simbólico da autoridade também guarda um gérmen fantasmático do lugar de exceção e de desmesura, isto é, de um pai primitivo que se coloca à parte da lei para fundá-la9. O que nos demonstra que, já em Freud, podemos compreender que a possibilidade da exceção e do arbítrio estão inscritas na cultura, não como uma regressão arcaica, mas como condição de possibilidade de nossas democracias.

Se parássemos aqui, teríamos todos os ingredientes para explicar o bolsonarismo como um neofascismo. Notemos, contudo, que no transcorrer desse mesmo texto, Adorno irá sustentar que a teoria freudiana permite igualmente compreender como essa matriz da propaganda nazista transformou-se em padrão latente de nossas democracias liberais, quando as estratégias de marketing do pósguerra começaram a se apropriar do fantasma do "pequeno grande homem", isto é, "uma pessoa que sugere, ao mesmo tempo, onipotência e a ideia de que ele é apenas mais um do povo, um simples, rude e vigoroso americano, não influenciado por riquezas materiais ou espirituais" (ADORNO, 2007, p.172).

O que Adorno pretendia demonstrar é que o fundamento dessa identificação não precisava mais ser de ordem simbólica como quisera Freud. Muito antes, a preponderância das identificações veiculadas então poderiam ser de ordem narcísica, fazendo com que o líder fosse uma espécie de "prolongamento da própria personalidade do sujeito, uma projeção coletiva de si mesmo" (ADORNO, 2007, p.172), que funcionaria como uma espécie de compensação imaginária aos múltiplos sofrimentos psíquicos vividos pelo sujeito.

Nesse sentido, entender a identificação a Bolsonaro como uma identificação narcísica passa inicialmente por compreender a estratégia de sua retórica e os efeitos subjetivos que ela veicula.

Apresentando-se como Mito, o ex-capitão, expulso do exército, faz carreira na política através da instrumentalização do discurso de ódio ("bandido bom é bandido morto", ou "de que a ditadura no Brasil deveria ter feito como Pinochet no Chile e matado 30 mil”). Com sua retórica patética que propaga a circulação do medo e da psicanalítica, em que ele distingue a noção de traço unário em Lacan e a noção de traço unariano na teoria dos conjuntos. 
insegurança, sua popularidade nunca havia conhecido alto índices até o ano de 2018. No entanto, a partir da ruptura democrática vivida a partir do impeachment da Presidente Dilma Rousseff, cujo processo, ainda que ininteligível, é apoiado pela maior parte da população brasileira, Bolsonaro começa figurar nas intenções de votos, como alternativa à rejeição ao Partido dos Trabalhadores.

Se o populismo fosse tão simplesmente uma operação das elites, teríamos atualmente um presidente do PSDB ou do PMDB no poder. Contudo, a ruptura democrática promovida pela insatisfação das oligarquias brasileiras com a política econômica de Dilma tem um preço alto, que se exprime na pulsionalidade e subjetividade do povo, abrindo um vazio representativo no espectro político que não poderia ser ocupado por nenhum ator situado em seus polos; nem pela esquerda que encontrava-se na posição de denúncia de um "golpe", cujo espaço semântico havia sido capturado pela mídia, e não realizava assim o luto da perda de seus líderes; nem da direita que após o festim da carnificina política, começava a ver seus principais nomes indiciados na Operação Lava-Jato.

Frente a esse contexto político, "Não fui eu" - a pichação encontrada nas ruas do Rio de Janeiro - é a resposta inconsciente que começa a se repetir como justificativa a todo tipo de "transgressão controlada" que autorize o bem comum, como bem formulou João Moreira Salles (2017). Não importa se a fonte é confiável ou não, o que importa é que eu não seja responsabilizado pelo estrago. Doravante, todo discurso de ódio será recodificado como o "ódio do bem", e uma disjunção entre retórica e ideologia passa a autorizar que frases, até então politicamente incorretas, sejam proferidas sem constrangimento público. Afinal de contas, "se o judiciário pode transgredir, em nome do bem comum, por que eu não posso?!". Nesse sentido, Bolsonaro entendeu melhor que ninguém que governar por clichês era a melhor forma de nos proteger de uma realidade que não entendemos, empregando as palavras de Hannah Arendt (1990), ainda muito longe da época dos memes, fakes News e trolls.

Contudo, a desresponsabilização ética do sujeito não é o único ingrediente dessa retórica. O que Bolsonaro conseguiu construir com seu discurso foi a possibilidade de que o patético (Phonyness, diria Adorno) instaurasse um novo espaço de verdade, por mais absurdo que isso possa soar. Um espaço de verdade pervertido, um espaço de verdade que serve somente para uma parcela da população, 
um espaço que, sem dúvida, não é novo (a metáfora aqui é o tio ou tia falastrões que falam impropérios no almoço de domingo, mas que ninguém nunca deu bola), mas um espaço que transformou nossa esfera pública. Atos homofóbicos, racistas e raivosos que outrora eram criticados e combatidos em nossa esfera pública passaram a ser sinônimos de espontaneidade, coragem e, sobretudo, sinceridade: todos aqueles predicados que faltam à classe política.

Bruno Carvalho (2018), em texto intitulado, Não foi Você, em resposta ao texto de Moreira Salles, realiza uma análise importante de como se operou uma mudança fundamental na retórica dos candidatos de ultra-direita nos Estados-Unidos. Quando um discurso xenófobo ou racista passa a não ser mais aceito como politicamente correto, ao invés de dizer que não querem morar perto de negros ou estrangeiros, candidatos republicanos passaram a proferir um discurso calcado numa pretensa liberdade individual: o Estado não pode me obrigar a viver com quem não quero. Transformando assim aquele que é opressor e violento em oprimido e vítima.

Certamente, Bolsonaro soube utilizar essa fonte inesgotável de insatisfações e descrença na classe política, através de uma retórica vitimista, em que ele, como qualquer brasileiro, estava cansado de corrupção e insegurança. Mas, assim como Trump, ele se deu conta de que poderia transpor esse limite ao, por exemplo, elogiar um torturador na sessão de votação do Impeachment de Dilma Rousseff na Câmara, chegando ao paroxismo com o episódio da facada em Juiz de Fora. São poucos os casos que podem oferecer tantos elementos para uma fonte de identificação narcísica: um homem que nos braços do povo é atacado, chegando à beira da morte, para retornar como herói. Nesse remake brasileiro da via sacra, ao passo que a recepção social se dividiu entre acusações de tentativa de assassinato orquestrada pela esquerda e uma suposta armação auto vitimizante da direita, testemunhamos absortos nossa cena política ser protagonizada, de forma definitiva, pela dimensão fanática da religião. Como em uma tragédia em três atos: após a instrumentalização da justiça, seguida pela ruptura democrática é a religiosização da política, isto é, a hipóstase da dimensão religiosa da crença, fanatismo, que captura nosso campo político.

Parêntese. Com isso, não procuramos reduzir o bolsonarismo totalmente à dimensão fanática. Não resta dúvidas de que a posição de líder que ele ocupa 
encontra em outras figuras suas suplências simbólicas: Justiça (Sérgio Moro), Economia (Paulo Guedes), Segurança (Hamilton Mourão). Algumas dessas fontes de autoridade que, inclusive, não são exploradas por Freud em seu ensaio de 1921. Mas o que essa "religiosização da política" nos mostra aqui é que se o líder constitui o povo, o povo igualmente constitui o líder: o episódio da facada, regido sob o signo do sacrifício, foi sua beatificação; e Bolsonaro, o nome a ocupar seu significante vazio.

\section{A IMPORTÂNCIA DA DESILUSÃo}

Antes de concluir, talvez valha a pena dar um passo atrás e lembrar as palavras com que Michel Temer começa seu primeiro discurso como presidente interino do Brasil. "O que queremos fazer agora com o Brasil é um ato religioso, um ato de religação de toda a sociedade brasileira com os valores fundamentais do nosso país". Nada mais pertinente para aquele que, após saciar a voracidade das oligarquias brasileiras, procura coesão e harmonia no abrigo da fé. No entanto, como lembra Giorgio Agamben (2005), a ideia da religião como religare (religação entre o reino dos homens e dos deuses) é uma noção amplamente mal utilizada em nossa modernidade laicizada. Religio seria antes a ação de vigiar constantemente para que esses reinos não fossem cruzados pelos homens.

No momento em que escrevemos esse ensaio, conhecemos um novo episódio que materializa o emprego sistemático da retórica da vitimização, deixando exposto o sintoma da "religiosização da política". A série de reportagens promovidas pelo Intercept Brasil que vaza as conversas de Telegram entre Deltan Dallangnol e Sério Moro, colocando em questão a imparcialidade e equidistância entre promotoria e investigação na operação Lava-Jato, gera instantaneamente uma divisão da opinião pública em torno da noção de vítima. Por um lado, os procuradores procuram invalidar qualquer análise do conteúdo das mensagens, alegando serem vítimas de uma ação ilegal. Argumento que é rapidamente denunciado pelo próprio Intercept, lembrando que os argumentos utilizados pela Operação Lava-Jato, ao vazar ilegalmente os áudios entre a então presidente Dilma e Lula, foram de que, entre a ilegalidade da forma de obtenção de dados e sua relevância pública, deve sempre prevalecer a relevância pública. Tentando assim colocar em xeque a tentativa de vitimização 
destes. Do outro lado, parte da esquerda busca imediatamente a libertação de Lula, como vítima de uma investigação ilegal, o que faria com que se recomeçasse o processo, abrindo precedente para anular uma série de etapas da operação.

Há poucos casos que demonstram com tamanha nitidez o quanto os polos do espectro político, ainda que separados em seus opostos, se encontram em posições subjetivas tão simétricas. E no entanto, o que perdemos de vista novamente são os efeitos perversos de uma política completamente dominada pela exceção e pelo arbítrio de um governo de milícia. O que fica fora da discussão é que a dimensão da verdade está capturada, mas está capturada não apenas pelo fanatismo de uma parcela da população que quer, apesar e contra tudo, crer; mas está capturada também pela falta de respostas de nossas instituições, que estão conhecendo um momento ímpar de imobilidade de sua autonomia para investigar e apurar esses fatos novos. Afinal de contas como entregar os leaks à Polícia Federal, sendo seu chefe o próprio acusado?

Em "Futuro de uma llusão", Freud (1927) defende que o trabalho científico seria o caminho para eliminar a ilusão religiosa, que abriga o homem do desamparo frente à sua finitude, intuindo que a religião perderia parte de sua influência sobre as massas. Com efeito, a leitura de Freud "deposita muita fé" na ciência, fazendo da ilusão religiosa uma etapa a ser ultrapassada pela posição de mestria da ciência. É nesse sentido que Lacan lembra que a revolução de Copérnico, ao substituir a terra pelo sol no centro do sistema solar, não seria completamente realizada sem a revolução newtoniana que subverte a estrutura do centro, por uma estrutura em elipse, com dois centros.

Já em seu texto sobre "Reflexões para os tempos de guerra e morte", Freud (1915), apresenta uma posição diferente que pode nos ajudar a pensar um caminho a tomar frente a esse fenômeno. Ante à guerra, o sujeito poderia conhecer duas posturas: a "desilusão" e/ou a "modificação da atitude". A desilusão seria uma reação que parte de um excesso de expectativa dos homens na civilização. No entanto, Freud critica tal sentimento engendrado pela desilusão como injustificado, na medida em que haveria uma dimensão "hipócrita" inerente à vida pulsional proveniente da ambivalência psíquica. 
Essa postura freudiana parece servir como advertência a nós mesmos nos tempos sombrios que vivemos. Como posicionarmo-nos frente a sujeitos que querem, apesar e contra tudo, crer? Certamente o pensamento, inconsciente ou não, de "eu avisei", traduzido pelos memes em "Jair me arrependendo", cruzou nossas cabeças. $E$, no entanto, o que testemunhamos é que essa predisposição, por parte da oposição, em antecipar um arrependimento, revela-se muitas vezes danosa e barra um processo dialético de desilusão e modificação de postura por parte dos sujeitos que se identificaram com o projeto de Bolsonaro. Nesse sentido, perguntamo-nos se há forma de realizarmos o luto de nossa democracia, sem experimentarmos nós mesmos a experiência de nossas desilusões, sem antecipá-la aos muitos sujeitos que ainda a experienciarão?

Frédéric Gros em "Desobediência" afirma que o "problema não é a desobediência, o problema é a obediência" (GROS, 2018, p.9). A preocupação do autor é discutir com que ética estamos lidando: "desobedecer não é só invocar uma legitimidade superior, afirmar que se obedece a outras leis, é pôr em causa o próprio princípio de legitimidade" (GROS, 2018, p.91).

A desobediência manifestava-se até Nuremberg como a manifestação de uma parte animal, estúpida e rude do homem que deveria ser punida. Com o julgamento de Adolf Eichmann a obediência é que foi punida. Inverteu-se a lógica de que a desobediência desumaniza, pois é "animal”, para uma obediência que desresponsabiliza, pois o ator cumpre ordens, tornando-se "não fui eu" que, ao não ser responsável, se abstém de uma ação ética.

A guisa de conclusão, propomos uma subversão da frase "não fui eu". Se por um lado, ela pode ser pensada como uma postura de desmentida, que se expia da responsabilização frente ao ato, por outro lado, podemos tomá-la como vários atosimagens que se repetem como um eco, uma repetição que introduz a criação.

Propomos pensar nesta segunda alternativa, como uma postura irônica que interpela o poder e a desresponsabilização, de forma que a repetição passa a ser uma possibilidade de produção de um "desvio" de sentido, como ressonância do dito (PORGE, 2015). Desvios de sentido repetidos e coletivizados que "pervertem" o desmentido, desfazem a mentira, invocando a legitimidade e responsabilidade de um ato de desobediência que promove religação. Se em ambos os polos deste fenômeno 
de religiosização da política for possível um processo de desilusão, onde a desobediência responsabilize a todos, será possível uma elaboração, ao modelo de um luto, exigência para a mudança no exercício democrático. 


\section{REFERÊNCIAS}

ADORNO, T. Teoria freudiana e o padrão da propaganda fascista. In. Ensaios sobre psicologia social e psicanálise. São Paulo: Unesp. 1977 [2007].

AGAMBEN, G. Profanações. São Paulo: Boitempo. 2007.

ARENDT, H. Origens do totalitarismo. São Paulo: Companhia das Letras. 1990.

BRUM, E. “Cem Dias sob o domínio dos perversos”. In: El País Brasil. São Paulo. 2019. Disponível em: https://brasil.elpais.com/brasil/2019/04/10/opinion/1554907780_837463.html Acesso em: 02 de Julho de 2019

CARVAlHO, B. "Não foi você". In: PIAUI. Vol. 142. São Paulo. Disponível em : https://piaui.folha.uol.com.br/materia/nao-foi-voce/. Acesso em: 02 de julho de 2019

FREUD, S. Edição standard brasileira das obras psicológicas completas de Sigmund Freud. Rio de Janeiro, RJ: Imago. 1996

. (1915). Reflexões para os tempos de guerra e morte. In: A história do movimento psicanalítico, Artigos sobre metapsicologia e outros trabalhos. . (1927). O futuro de uma ilusão. Vol XXIV (1932) Por que a guerra? Vol.XXII.

FREUD, S. Nouvelles conferences sur la psychanalyse. Paris, Gallimard. 1971[1932].

GROS, F. Desobedecer. São Paulo: Ubu Editora. 2018.

LACLAU, E. A razão populista. São Paulo: Três Estrelas. 2013.

LAGO, M. "Procura-se um Presidente”. In: PIAUI. Vol.152. São Paulo. 2019. Disponível em : https://piaui.folha.uol.com.br/materia/procura-se-um-presidente/ Acesso em: 02 de Julho de 2019

ONFRAY, M. Le crépuscule d'une idole. Paris, Grasset, 2009.

PORGE, E. Entre voces y silencios. In: LaPsus Calami: la Angustia y lo Unheimliche. Convergencia - Movimento Lacaniano por el Psicoanálisis Freudiano. Buenos Aires: Letra Viva Editorial, 2015.

ROUDINESCO, E. Freud - mas por que tanto ódio? Rio de Janeiro: Zahar, 2011.

SALLES, J. Anotações sobre uma pichação. In: PIAUI. Vol. 139. São Paulo. 2018. Disponível em https://piaui.folha.uol.com.br/materia/anotacoes-sobre-uma-pichacao/ Acesso em: 02 de Julho de 2019 


\section{Psychoanalysis And Politics: The Work OF DESILLUSIONMENT}

\section{Abstract}

The present essay proposes to discuss the ethical stance that psychoanalysis inherits from Sigmund Freud on how to position oneself in the face of authoritarian political phenomena. Initially, we carry out a reading of the bolsonarismo from a revision of the mechanism of identification to the leader proposed by Freud. For that, the notions of fascism and populism, developed respectively by Theodor Adorno and Ernesto Laclau, were chosen, decanting three fundamental operators to the emergence of this phenomenon: narcissistic identification, victimistic rhetoric and "religiosization of politics". Finally, we discuss the importance of the work of disillusionment as a necessary condition for the elaboration of the need for belief.

KEYWORDS : Identification ; disillusionment ; fascism ; populism. 


\section{Psychanalyse Et Politique: Le Travail De La DesiLlusion}

\section{RÉSUMÉ}

Le présent essai propose de discuter de la position éthique que la psychanalyse hérite de Sigmund Freud concernant la manière de se positionner face à des phénomènes politiques autoritaires. Dans un premier temps, nous avons procédé à une lecture du bolonarisme à partir d'un examen critique du mécanisme d'identification proposé par Freud. Pour cela, les notions de fascisme et de populisme, développées respectivement par Theodor Adorno et Ernesto Laclau, ont été retenues, décantant trois opérateurs que nous considérons comme fondamentaux pour l'apparition de ce phénomène: l'identification narcissique, la rhétorique victimiste et la religiosité politique. Enfin, nous discutons de l'importance du travail de désillusion en tant que condition nécessaire à l'élaboration du besoin de la croyance.

MoTS-ÉCLÉs: Identification ; désillusion ; fascisme ; populisme. 
Psicanálise E Política: O Trabalho da Desilusão

(C) 2019 Psicanálise \& Barroco em revista

http://www.seer.unirio.br/index.php/psicanalise-barroco/index revista@psicanaliseebarroco.pro.br

Programa de Pós-Graduação em Memória Social — UNIRIO

Memória, Subjetividade e Criação

www.memoriasocial.pro.br/proposta-area.php 